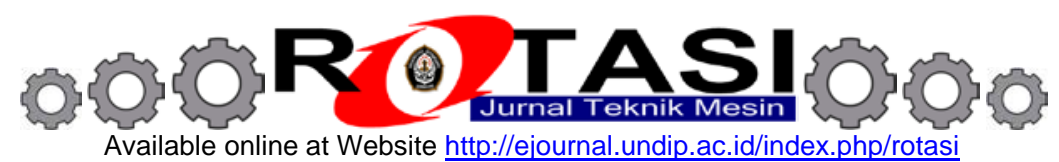

\title{
Pengujian Pengeringan Garam Briket Skala Laboratorium
}

\author{
*Berkah Fajar Tamtomo Kiono ${ }^{a}$, Severianus Sony ${ }^{\mathbf{b}}$ \\ ${ }^{a}$ Dosen Departemen Teknik Mesin, Fakultas Teknik, Universitas Diponegoro \\ ${ }^{\mathrm{b}}$ Mahasiswa Program Studi S-1 Departemen Teknik Mesin, Fakultas Teknik, Universitas Diponegoro \\ Jl. Prof. Sudharto, SH., Tembalang-Semarang 50275, Telp. +62247460059 \\ *E-mail: berkahfajar@undip.ac.id
}

\begin{abstract}
Abstrak
Tingginya konsumsi garam beryodium di Indonesia, membuat pemerintah membuat dan mendorong UMKM untuk memproduksi garam beryodium pada jumlah besar. Salah satu provinsi yang mempunyai jumlah UMKM garam yang banyak adalah Provinsi Jawa Tengah. Daerah terbesar produksi garam beryodium adalah Kabupaten Pati. Namun untuk memiliki produktivitas yang tinggi, pabrik garam beryodium yang ada di Pati harus mengganti alat pengeringnya dengan alat pengering yang tepat. Salah satu alat pengering yang harus diganti adalah alat pengering untuk garam briket. Dalam mendesain suatu alat pengering untuk garam briket, perlu dilakukan penelitian mengenai pengeringan garam briket skala laboratorium untuk mengetahui parameter-parameter untuk pengeringan garam. Penelitian ini dilakukan dengan menggunakan oven. Garam dikeringkan dengan menggunakan 1 heater dan 2 heater. Variasi temperatur oven dengan mengubah bukaan damper. Bukaan damper diatur setengah bukaan dan bukaan penuh (WOT/Wide Opening Throttle). Temperatur oven bervariasi dari $120^{\circ} \mathrm{C}$ sampai $190^{\circ} \mathrm{C}$, sedangkan temperatur garam maksimum adalah $108^{\circ}$ C.Titik didih garam sangat tingi yaitu $801,1^{\circ} \mathrm{C}$, sedangkan titik didih Yodium adalah $184,4^{\mathrm{O}} \mathrm{C}$. Pengujian ini mendapatkan hasil pengeringan berturut-turut sebagai berikut, dengan suhu udara akhir $120^{\circ} \mathrm{C}$ membutuhkan waktu pengeringan selama 221 menit, sedangkan untuk suhu $130^{\circ} \mathrm{C}$ waktu pengeringannya adalah 200 menit, dengan suhu akhir $176^{\circ} \mathrm{C}$ adalah 55 menit, dan pengeringan dengan suhu akhir $200^{\circ} \mathrm{C}$ adalah 55 menit. Proses pengeringan optimum garam pada suhu $170-180^{\circ} \mathrm{C}$ dengan waktu pengeringan 19 menit.
\end{abstract}

Kata kunci: pengering, garam bata.

\section{Pendahuluan}

Bahan pangan merupakan kebutuhan pokok bagi manusia di samping pendidikan, kesehatan, dan sandang lainnya. Garam merupakan salah satu kebutuhan yang merupakan pelengkap dari kebutuhan pangan dan merupakan sumber elektrolit bagi tubuh manusia.Garam merupakan salah satu komoditas strategis karena selain merupakan kebutuhan manusia, juga digunakan sebagai bahan baku industri, salah satunya industri-industri makanan kemasan. Untuk kebutuhan garam konsumsi manusia, garam telah dijadikan sarana fortifikasi zat yodium menjadi garam konsumsi beryodium dalam rangka penanggulangan Gangguan Akibat Kekurangan Yodium (GAKY). Garam merupakan salah satu sumber sodium dan klorida dimana kedua unsur tersebut diperlukan untuk metabolisme manusia.

Kebutuhan garam nasional dari tahun ke tahun semakin meningkat seiring dengan pertambahan penduduk dan perkembangan industri di Indonesia. Hal itu terlihat dari kenaikkan import garam konsumsi dari tahun 2009 sebesar 99.574 ton, lalu pada tahun 2010 sebesar 597.583 ton, dan pada tahun 2011 menjadi 923.756 ton. Hal ini menjadikan indikator bahwa produksi garam di dalam negeri masih kurang dari kebutuhan nasional. Kebutuhan total nasional untuk garam pada tahun 2009 sebesar 2.960.250 ton, pada tahun 2010 sebesar 3.003.550 ton, dan pada tahun 2011 menjadi 3.323.206 ton [1].

Pada proses pengeringan garam, garam dikeringkan dari air laut menggunakan cahaya matahari, setelah itu garam dicuci dengan larutan air garam pada kolam-kolam yang terdapat didalam pabrik garam, kemudian garam dikeringkan kembali. Setelah menjadi garam dengan butir yang halus, garam diberikan larutan yodium. Maka diperlukannya proses pengeringan kembali agar tidak ada kandungan air pada garam. Pengeringan garam bertujuan supaya garam tidak rusak ketika ditransportasikan. Kandungan air didalam garam briket disarankan sekitar 5\%, supaya garam tidak terklu kuat, sehingga garam masih dapat dihancurkan ketika akan digunakan di rumah tangga.

Pada proses pengeringan garam yang ada di Kabupaten Pati, metode pengeringan yang digunakan untuk mengeringkan garam yaitu pengeringan alami menggunakan panas dari sinar matahari (sun drying) dan pengeringan buatan (artificial drying). Sun drying memerlukan sinar matahari sebagai sumber. Sun drying ini dilakukan untuk mengeringkan garam dari air laut, lalu untuk pengemasannya dikeringkan kembali dengan artificial drying. Pengeringan buatan (artificial drying) menggunakan bahan bakar. Pengeringan yang berlebihan akan menyebabkan pemborosan energi dan kekuatan garam briket akan menjadi sangat tinggi.

Pemerintah mendorong petani-petani garam dan pengolah garam untuk memproduksi garam dalam jumlah banyak untuk mengatasi kebutuhan garam di Indonesia yang tinggi. Proses pengeringan garam menjadi sangat penting 
karena menentukan produktivitas petani garam. Di Kabupaten Pati banyak perusahaan garam, dimana garam diolah untuk diberikan Yodium dan dikeringkan kembali dan dikemas. Garam yang dihasilkan oleh pabrik garam yang ada di Kabupaten Pati ada yang berbentuk bubuk dan berbentuk bata (briket). Karena kebutuhan produktivitas yang tinggi maka dibutuhkan teknologi pengering yang tepat guna. Keadaan pengering yang ada di Kabupaten Pati dengan mengunakan pembakaran langsung belum berhasil meningkatkan produktivitas mereka. Salah satu produk yang paling laku di pasaran adalah garam yang tipe bata (briket). Karena kebutuhan garam tipe bata (briket) yang tinggi maka perlu dibuatnya pengering garam briket yang tepat guna bagi petani-petani garam di Pati. Pengering yang ada di Kabupaten Pati masih menggunakan bahan bakar solar, sedangkan bahan bakar tersebut tidak boleh digunakan untuk pengeringan (dibakar langsung), karena ditujukan untuk sarana transportasi. Maka pabrik garam di Kabupaten Pati perlu mengubah menjadi bahan bakar gas LPG. Pada proses pengubahan bahan bakar solar menjadi LPG, pihak Pertamina dan Pemkab Pati menginginkan pengering yang ada di pabrik-pabrik garam menjadi efisien. Pada proses desain pengering garam menggunakan panas untuk kabupaten Pati, diperlukan pengujian pengeringan skala laboratorium atau uji thermogravimetry untuk mendapatkan parameter- parameter pengeringan garam, serta tingkat kekeringan garam seperti yang ada di pasaran sekarang [2].

Tujuan dari pengujian garam skala laboratorium ini mendapatkan parameter-parameter yang menjadi dasar dalam pembuatan mesin pengeringan garam. Waktu yang dibutuhkan untuk mengeringkan garam, suhu udara optimum dalam proses pengeringan garam karena keterbatasan dengan titik didih dari yodium, suhu didalam briket garam, tingkat kekuatan yang dihasilkan dari pengeringan garam untuk dibandingkan dengan kekuatan garam yang ada di pasaran merupakan parameter yang diuji dalam uji pengeringan garam skala laboratorium ini.

Kandungan air yang ada didalam garam sangat berpengaruh terhadap nilai kekuatannya, agar garam tidak rusak saat didistribusikan maka kandungan airnya harus dikurangi. Namun bila kandungan airnya terlalu kering, maka garam akan menjadi sangat kuat untuk dihancurkan ketika hendak dikonsumsi. Kandungan air yang terlalu rendah pada garam briket tidak diinginkan karena sangat sulit untuk dikonsumsi, sehingga dalam proses pengujian pengeringan garam briket skala laboratorium perlu dicari proses pengeringan garam yang dapat menghasilkan dengan garam yang ada di pasaran sehingga konsumen tidak sulit mengkonsumsinya juga tidak rusak ketika didistribusikan.

\section{Material dan metode penelitian \\ 2.1 Diagram alir metode penelitian}

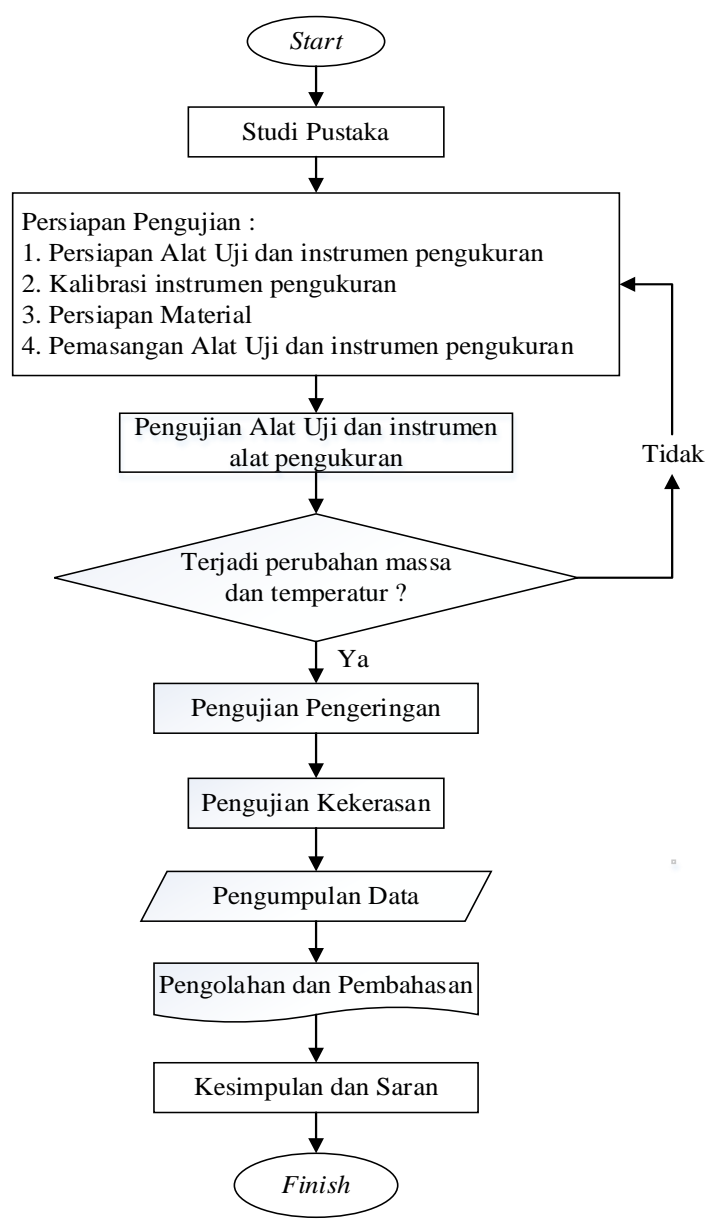

Gambar 1. Diagram alir metode penelitian 
Tahap pertama adalah pembuatan alat pengering dan persiapan alat-alat pengujiannya. Setelah itu garam briket basah ditimbang untuk mengetahui massa awal. Lalu garam briket tersebut dimasukkan kedalam oven. Oven dinyalakan dengan variasi penyalaan heater dan bukaan throttle damper. Ketika proses pengeringan berjalan, maka timbangan pada oven akan mengukur massa awal, perubahan, hingga massa akhir dari proses pengeringan garam. Untuk membandingkan kekuatan garam yang ada di pasaran dengan garam yang dikeringkan sendiri, maka perlu diuji menggunakan mesin uji tekan, juga untuk mengetahui lama proses pengeringan untuk menghasilkan garam di pasaran. Kemudian pengujian dilakukan kembali untuk membuktikan prediksi waktu dan suhu pengeringan untuk menghasilkan garam yang sama seperti di pasaran. Lalu data-data tersebut diolah dan dianalisa.

\subsection{Set-up alat uji}

Pada set up alat uji, bisa dilihat pada gambar 4 dibawah ini.

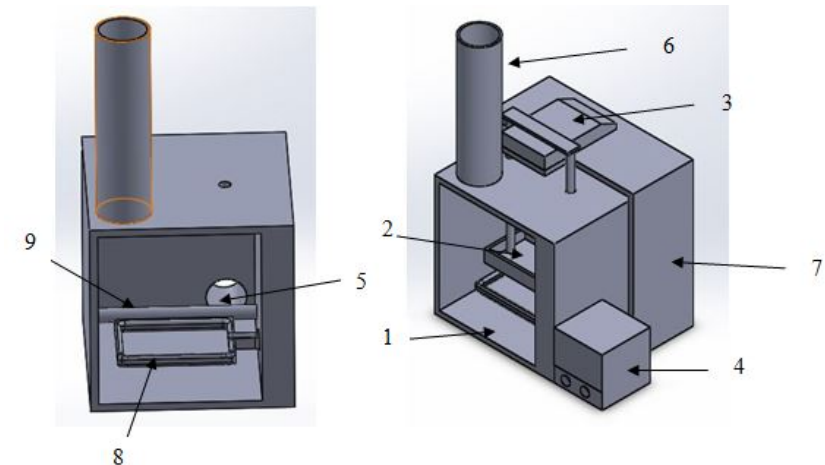

Gambar 2. Skema set up alat

Keterangan : 1 . Oven

2. Nampan Garam

3. Timbangan

4. Thermodisplay

5. Intake Udara

6. Exhaust

7. Dudukan Timbangan

8. Heater 1

9. Heater 2.

Oven dan heater untuk memanaskan material garam. Timbangan digunakan untuk mengukur massa awal, perubahan dan massa akhir garam. Dudukan timbangan berfungsi agar timbangan tidak berubah posisi, intake sebagai udara masuk dan exhaust sebagai lubang udara keluar.

Pada makanan, kandungan air dan RH mempengaruhi nilai kekuatan dari makanan. Ini disebabkan karena air mempengaruhi kedalam ikatan antar kristal garam[2].

Pengujian dilakukan dengan memanaskan material garam dengan kondisi pemanasan dari suhu udara lingkungan hingga pada suhu udara pemanas tertentu dijaga konstan. Ha ini berkaitan dengan uji termogravimetri material dengan perlakuan pemanasan, dimana suhu udara dipanaskan hingga penahanan suhu pada suhu tertentu [3].

Untuk menguji dan membandingkan kekuatan garam yang dikeringkan digunakan mesin uji tekan. Mesin uji tekan yang digunakan adalah mesin uji tarik dan tekan tipe GD-1100 . Bisa dilihat pada Gambar 3 [4].

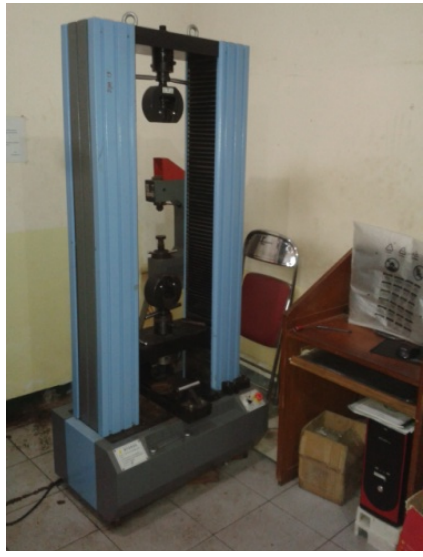

Gambar 3. Mesin uji tekan GD-1100 


\section{$2.3 \quad$ Variasi pengujian}

Pada percobaan dilakukan dengan variasi temperatur. Variasi temperatur ini dilakukan dengan menggunakan 1 heater dan 2 heater dengan mengatur bukaan throttle damper. Variasi bukaan damper yang digunakan adalah full open throttle single heater, half open throttle single heater, full open throttle double heater, half open throttle double heater. Perbedaan variasi bukan throttle mempertinggi temperatur hingga $10^{\circ} \mathrm{C}$, hal ini membuat perbedaan dalam waktu pengeringan. Lalu mendapatkan temperatur udara onset dimana temperatur tersebut adalah temperatur dimana perubahan massa terbesar [3].

\section{Hasil dan pembahasan}

\subsection{Pengujian pengeringan dengan 1 Heater hingga Massa Steady}

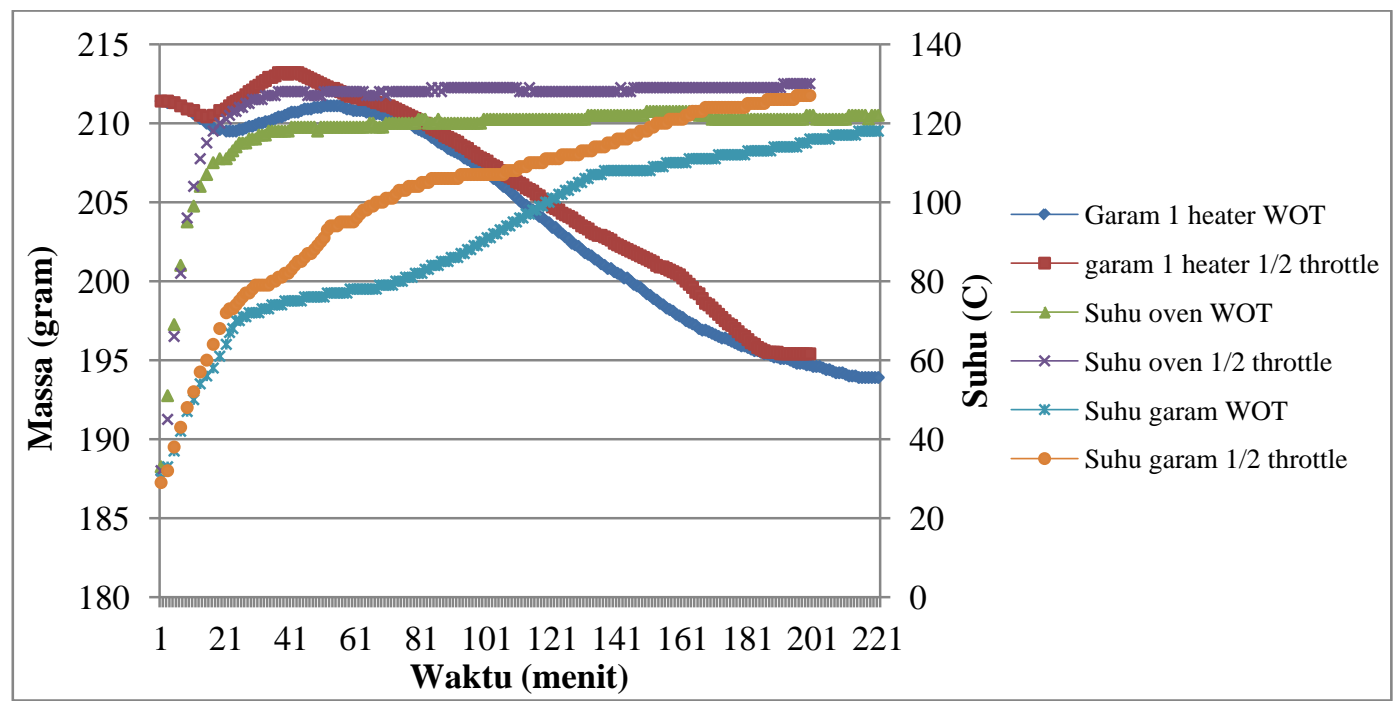

Gambar 4. Grafik Pengujian Gabungan 1 Heater

Gambar 4 menunjukan pengeringan garam dengan 1 heater. Garam yang dikeringkan dengan 1 heater dan bukaan throttle damper penuh memiliki waktu pengeringan 210 menit, serta suhu udara oven akhir adalah $120^{\circ} \mathrm{C}$. Pada garam yang dikeringkan dengan 1 heater dan bukaan throttle damper setengah, memiliki waktu pengeringan yang lebih cepat, yakni 200 menit dengan suhu udara akhir setinggi $130^{\circ} \mathrm{C}$. Ini disebabkan karena pada bukaan throttle damper setengah memiliki suhu udara untuk memanaskan material lebih tinggi. Pada pengeringan dengan 1 heater dan bukaan throttle penuh memiliki T udara onset $120^{\circ} \mathrm{C}$. Pada pengeringan dengan 1 heater dan bukaan throttle setengah memiliki temperatur udara onset sebesar $130^{\circ} \mathrm{C}$.

\subsection{Pengujian pengeringan dengan 2 Heater hingga Massa Steady}

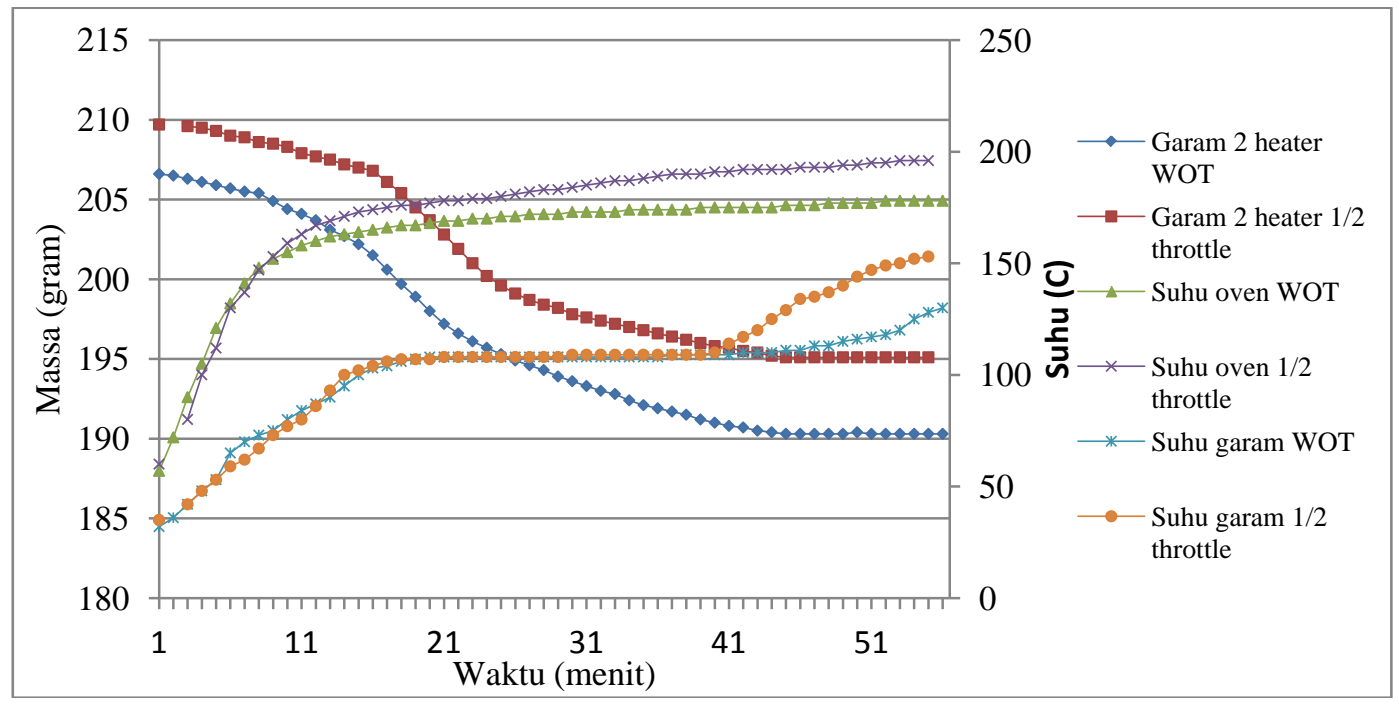

Gambar 5. Grafik Pengujian Gabungan 2 Heater 
Pada Gambar 5 terlihat bahwa garam lebih cepat mencapai steady. Pada pengeringan dengan 2 heater dan bukaan throttle damper penuh, garam membutuhkan waktu hingga mencapai steady selama 55 menit. Pada pengeringan dengan 2 heater dan bukaan throttle setengah, garam membutuhkan waktu selama 55 menit pula untuk mencapai steady. Pada pengeringan dengan 2 heater dan bukaan throttle penuh, memiliki titik onset temperatur udara pada $170^{\circ} \mathrm{C}$. Pada 2 heater dan bukaan throttle setengah memiliki temperatur udara onset lebih tinggi, yakni $190^{\circ} \mathrm{C}$.

\subsection{Pengujian pengeringan hingga Massa Garam kembali ke Massa Awal.}

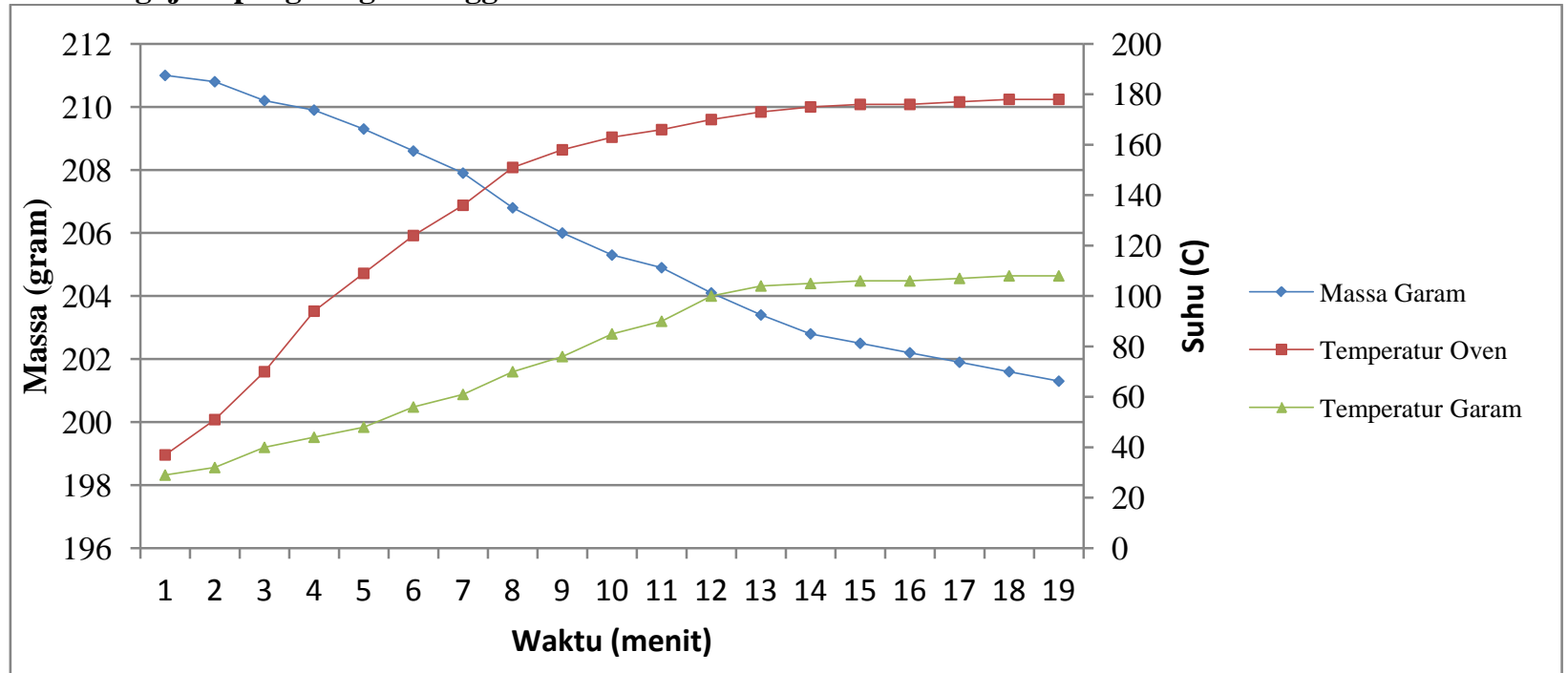

Gambar 6. Pengujian hingga massa garam kembali ke massa awal

Untuk pengujian ini dilakukan dengan menggunakan garam yang ada dipasaran sebagai acuan kandungan air garam. Pada pengujian pengeringan, garam tersebut ditimbang terlebih dahulu massanya, lalu direndam dengan larutan garam. Massa garam awal adalah 201,3 g. Setelah direndam larutan garam dalam waktu 15 menit, massa garam menjadi 211 g, kemudian garam dimasukkan kedalam oven. Garam basah tersebut kembali ke massa awal setelah pengeringan 19 menit dengan suhu udara akhir $180^{\circ} \mathrm{C}$. Kandungan air garam setelah pengeringan adalah 4,7\%. Temperatur garam maksimum $108^{\circ} \mathrm{C}$, masih dibawah temperatur didih yodium $184,4^{0} \mathrm{C}$.

\subsection{Uji kekuatan Garam}

Gambar 7 menunjukan grafik uji kekuatan pada garam yang dikeringkan dengan 1 heater bukaan throttle damper penuh, 1 heater bukaan throttle damper setengah, 2 heater bukaan throttle damper setengah, serta 2 heater bukaan throttle damper setengah, garam yang ada di pasaran serta garam yang dikeringkan hingga mencapai massa awal sebelum dibasahi. Uji kekuatan ini menggunakan alat uji tekan. Sifat-sifat yang didapatkan dari alat pengujian tekan adalah grafik tegangan-regangan dari masing-masing garam, lalu nilai tegangan tensile masing-masing garam. Kekuatan dilihat dari nilai tegangan tensile masing-masing garam karena garam briket merupakan material yang sangat getas dan uji kekuatan ini untuk membuktikan kekuatan ikatan antar garam pada garam briket yang mana sangat dipengaruhi oleh kandungan air didalam garam briket [2].

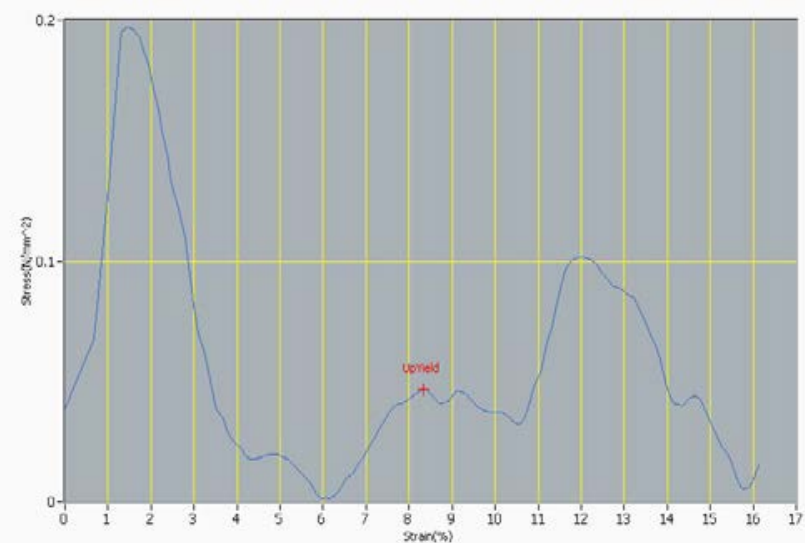

(a)

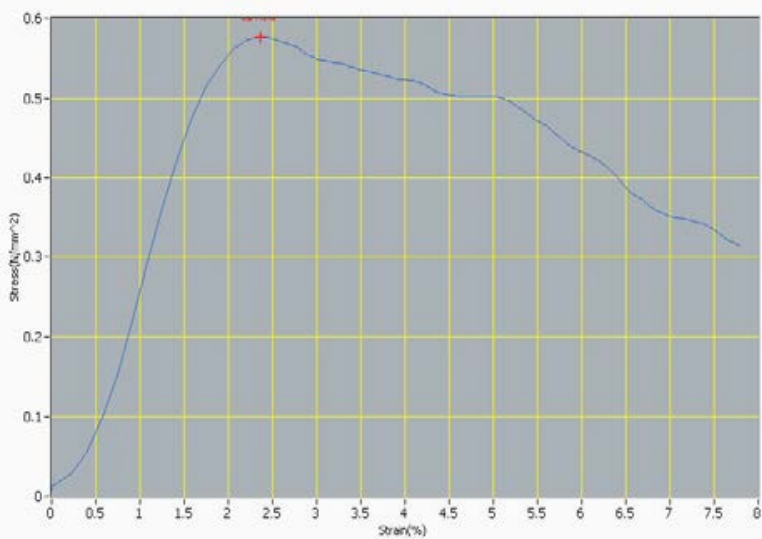

(b) 


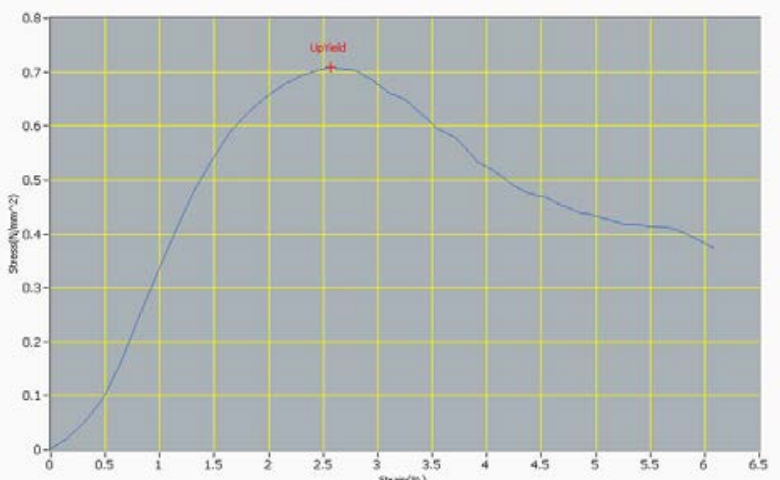

(c)

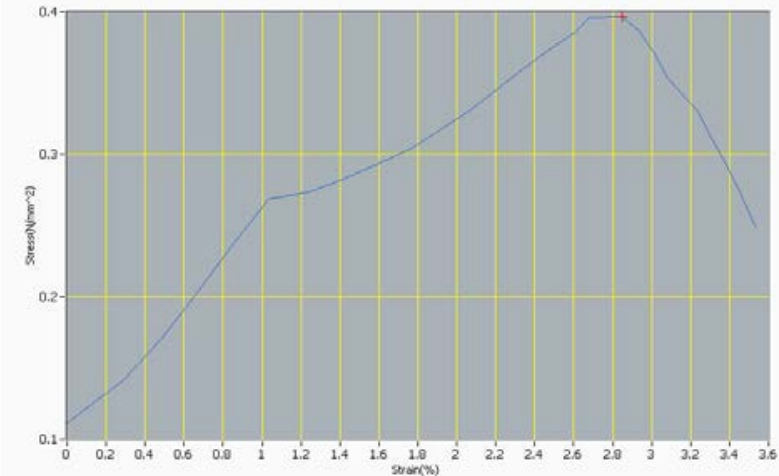

(e)

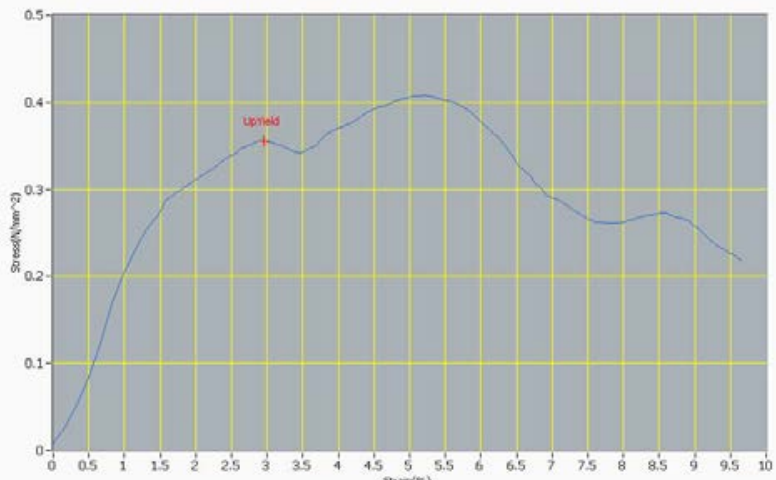

(d)

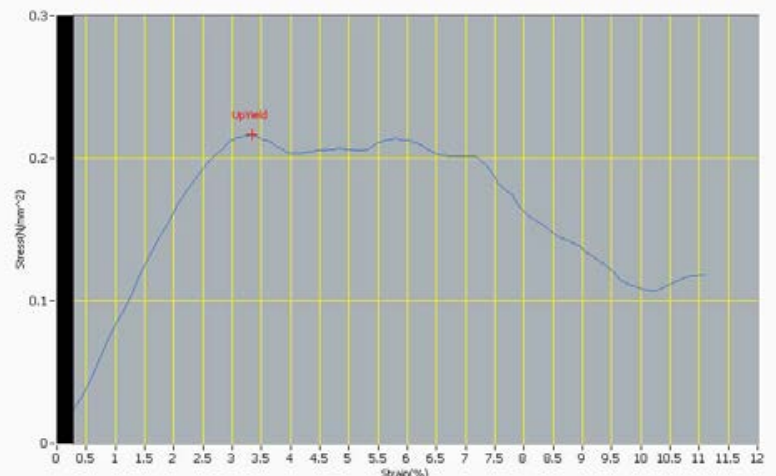

(f)

Gambar 7. Diagram tegangan regangan (a) garam di pasaran, (b) pengeringan hingga massa steady dengan 1 heater bukaan throttle penuh, (c) pengeringan hingga massa steady dengan 1 heater bukaan throttle setengah, (d) pengeringan hingga massa steady 2 dengan heater bukaan throttle setengah, (e) pengeringan hingga massa steady dengan 2 heater bukaan throttle setengah, (f) pengeringan garam hingga kembali ke massa awal sebelum dibasahi

\section{Kesimpulan}

Proses pengeringan garam optimum pada percobaan ini adalah $180^{\circ} \mathrm{C}$ ini berhubungan dengan temperatur maksimal dari alat pemanas. Berdasarkan percobaan, untuk mendapatkan tingkat pengeringan garam yang adalah suhu udara $180^{\circ} \mathrm{C}$ dengan prediksi waktu pengeringan selama 19 menit. Garam yang dikeringkan hingga massa steady mempunyai nilai kekuatan dengan garam yang ada di pasaran, hal ini menunjukan kandungan air pada garam tersebut mempunyai nilai 4,7\% yang sama dengan garam yang ada di pasaran. Lalu nilai kekuatan tensile strength garam berkisar 0.196-0,216 N/mm².

\section{Daftar pustaka}

[1] Rochwulaningsih, Y. 2012. Membongkar Persoalan Struktural Tata Niaga Garam Rakyat. Strategi Pembangunan Usaha Garam. Semarang: 15 oktober.

[2] Jakubcyzk, E., et all. 2008. Relationship Between Water Activity Of Crisp Bread and its Mechanical Properties and Structure. Warsaw: Department of Food Engineering and Process Management Warsaw University of Life Sciences.

[3] Foldvary, M., 2011. Handbook of thermogravimetric system of minerals and its use in geological practice. Budapest : Geological Institute of Hungary.

[4] Jobsheet praktikum metfis 2013 